AUTHOR CORRECTION OPEN

\title{
Author Correction: The reproducibility crisis in the age of digital medicine
}

\author{
Aaron Stupple ${ }^{1,2}$, David Singerman ${ }^{3}$ and Leo Anthony Celi $\mathbb{D}^{2,4}$ \\ npj Digital Medicine (2019)2:19; https://doi.org/10.1038/s41746-019-0098-9
}

Correction to: npj Digital Medicine https://doi.org/10.1038/ s41746-019-0079-z, Published online 29 January 2019

In the original version of the published Article, there was a sentence fragment prior to the last sentence under the subheading "Reproducibility and digital medicine" which stated "Some journals, such as PLOS ONE, have made an early". To improve clarity, the sentence fragment has been removed. This has been corrected in the HTML and PDF version of the Article.

Open Access This article is licensed under a Creative Commons Attribution 4.0 International License, which permits use, sharing, adaptation, distribution and reproduction in any medium or format, as long as you give appropriate credit to the original author(s) and the source, provide a link to the Creative Commons license, and indicate if changes were made. The images or other third party material in this article are included in the article's Creative Commons license, unless indicated otherwise in a credit line to the material. If material is not included in the article's Creative Commons license and your intended use is not permitted by statutory regulation or exceeds the permitted use, you will need to obtain permission directly from the copyright holder. To view a copy of this license, visit http://creativecommons. org/licenses/by/4.0/.

(c) The Author(s) 2019

${ }^{1}$ Baystate Medical Center, Springfield, MA, USA; ${ }^{2}$ Beth Israel Deaconess Medical Center, Boston, MA, USA; ${ }^{3}$ University of Virginia, Charlottesville, VA, USA and ${ }^{4}$ Massachusetts Institute of Technology, Cambridge, MA, USA

Correspondence: Leo Anthony Celi (Iceli@mit.edu)

Published online: 19 March 2019 